\title{
Impact of aerosol composition on cloud condensation nuclei activity
}

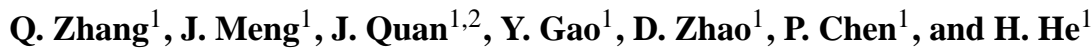 \\ ${ }^{1}$ Beijing Weather Modification Office, Beijing, China \\ ${ }^{2}$ Institude of Urban Meteorology, CMA, Beijing, China \\ Correspondence to: J. Quan (quanjn1975@gmail.com)
}

Received: 24 October 2011 - Published in Atmos. Chem. Phys. Discuss.: 17 January 2012

Revised: 23 March 2012 - Accepted: 2 April 2012 - Published: 25 April 2012

\begin{abstract}
The impact of aerosol composition on cloud condensation nuclei (CCN) activity were analyzed in this study based on field experiments carried out at downtown Tianjin, China in September 2010. In the experiments, the CCN measurements were performed at supersaturation (SS) of $0.1 \%, 0.2 \%$ and $0.4 \%$ using a thermal-gradient diffusion chamber (DMT CCNC), whereas the aerosol size distribution and composition were simultaneously measured with a TSI SMPS and an Aerodyne Aerosol Mass Spectrometer (AMS), respectively. The results show that the influence of aerosol composition on CCN activity is notable under low SS $(0.1 \%)$, and their influence decreased with increasing SS. For example, under SS of $0.1 \%$, the CCN activity increases from $4.5 \pm 2.6 \%$ to $12.8 \pm 6.1 \%$ when organics fraction decrease from $30-40 \%$ to $10-20 \%$. The rate of increase reached up to $184 \%$. While under SS of $0.4 \%$, the CCN activity increases only from $35.7 \pm 19.0 \%$ to $46.5 \pm 12.3 \%$ correspondingly. The calculated $N_{\mathrm{CCN}}$ based on the sizeresolved activation ratio and aerosol number size distribution correlated well with observed $N_{\mathrm{CCN}}$ at high SS $(0.4 \%)$, but this consistence decreased with the falling of SS. The slopes of linear fitted lines between calculated and observed $N_{\mathrm{CCN}}$ are $0.708,0.947$, and 0.995 at SS of $0.1 \%, 0.2 \%$ and $0.4 \%$ respectively. Moreover, the stand deviation (SD) of calculated $N_{\mathrm{CCN}}$ increased with the decreasing of SS. A case study of $\mathrm{CCN}$ closure analyses indicated that the calculated error of $N_{\mathrm{CCN}}$ could reach up to $34 \%$ at SS of $0.1 \%$ if aerosol composition were not included, and the calculated error decreased with the raising of SS. It is decreased to $9 \%$ at SS of $0.2 \%$, and further decreased to $4 \%$ at SS of $0.4 \%$.
\end{abstract}

\section{Introduction}

Part of aerosol particles can act as cloud condensation nuclei $(\mathrm{CCN})$, which will affect cloud formation (Ramanathan et al., 2001; Andreae et al., 2004), including cloud droplet number concentration and their size (Jin and Shepherd, 2008; Rosenfeld et al., 2008; Zhang et al., 2011). The complexities of aerosol particles make it rather difficult to estimate their CCN activity (Cruz and Pandis, 1998; Hegg et al., 2001; Prenni et al., 2001; Brooks et al., 2003; Kumar et al., 2003; Raymond and Pandis, 2003; Broekhuizen et al., 2004; Marcolli et al., 2004; Henning et al., 2005), which resulted that the impact of aerosol on cloud and the cloud feedbacks are currently considered as the largest uncertainty in climate system (IPCC, 2007).

The ability of an aerosol particle to become droplet is primarily a function of their size and chemical composition (Seinfeld and Pandis, 2006). Köhler theory describes the competing effects involved in cloud droplet activation. Two competing effects determine the equilibrium vapor pressure of water over an aqueous solution droplet: the solution effect (Raoult's law) which tends to decrease the equilibrium vapor pressure on the droplet and the curvature (Kelvin's law) effect which tends to increase the equilibrium vapor pressure on the droplet. Comparing with organics, the solubility of inorganic salts are much higher, which make the inorganic salts are easier to be activated. For example, the critical supersaturation $(\mathrm{Sc})$ needed to activate the particles of ammonium sulfate and adipic acid with size of $100 \mathrm{~nm}$ are $0.15 \%$ and $0.27 \%$ respectively (Hings et al., 2008). Moreover, the presence of slight soluble aerosol particles or soluble gases will further decrease the Sc (Kulmala et al., 1997). The work of Kulmala et al. (1997) reveals that stable cloud droplets of size $1-10 \mu \mathrm{m}$ could exist in air with a relative humidity 
of less than $100 \%$. Therefore, the SS should be concerned during the experiment in studying the effect of aerosol composition on CCN activation. If the SS was set too high, the component properties of aerosol particles might be covered.

In this study, a field experiment was conducted in a heavy pollution area located in north China plain (NCP). During the experiment, the aerosol number size distribution, composition (sulfate, nitrate, ammonium, chlorite, organics), and the size-resolved activation ratio under different SS $(0.1-0.4 \%)$ were measured. A large variability of the ratio of organics to inorganic salts was observed during the field experiment, providing a good opportunity to study the effect of aerosol composition on CCN activity under different SS.

\section{Experimental methods}

\subsection{Aerosol sampling site}

The sampling site is situated in the northwest of the urban area of Tianjin, and the measurements were conducted continuously from 1 September to 26 September 2010. The monitoring instruments were deployed on monitor station with no high building around. A main road about $20 \mathrm{~m}$ away to the north passes by the monitor station, and no significant pollution sources exist near the sampling site.

During the campaign, sampling of aerosol was conducted from the top of the sampling room via a PM2.5 cyclone inlet which can remove coarse particles more than $2.5 \mu \mathrm{m}$. To minimize sampling losses, a stainless steel pipe, approximately $1 / 4$ inch in diameter, is used to introduce air stream into the room. During the campaign, the air-conditioned room temperature is $\sim 21^{\circ}$ and the sampling air relative humidity (RH) is maintaining below $30 \%$ after passing through two diffusion dryers.

\subsection{Instrument setup}

Polydisperse dry aerosol is charge-neutralized using a $\mathrm{Kr}$ 85 neutralizer (TSI 3077A) and introduced into a differential mobility analyzer (DMA, TSI 3081L) for classification by electrical mobility. The classified aerosol is then split into a condensation particle counter (CPC, TSI 3776) to measure the particle size distribution and the total aerosol concentration (condensation nuclei, $\mathrm{CN}$ ), and a DMT doublecolumn continuous-flow CCN counter (CCN-200) (Roberts and Nenes, 2005; Lance et al., 2006) to obtain the CCN activation properties. The particle size distribution was measured every $5 \mathrm{~min}$, with an up-scan time of $280 \mathrm{~s}$. The DMA was operated with $0.81 \mathrm{~min}^{-1}$ sample air flow rate which was split into two parts with $0.51 \mathrm{~min}^{-1}$ for $\mathrm{CCN}$ counter and $0.31 \mathrm{~min}^{-1}$ for $\mathrm{CPC}$, and a closed-loop sheath air flow rate of $81 \mathrm{~min}^{-1}$. The sheath flow rate was continuously regulated to a constant volumetric flow, using a mass flow controller with continuously pressure and temperature compensated mass flow set point. All flow rates were regularly checked and sizing accuracy was checked by employed Polystyrene latex (PSL) spheres with different diameter.

The CCN-200 has two columns to measure different samples at different supersaturations (SS) at the same time. In the field experiment, column A directly measures the dry polydisperse aerosol sample to obtain the bulk CCN concentration, while column B connects to the exit of DMA to measure the size-resolved particles activation properties. The $\mathrm{CCN}-200$ was operated at a total flow rate of $11 \mathrm{~min}^{-1}$ with a sheath-to-aerosol flow ratio of 10 . Both columns operated at the same SS at the same time. One measurement cycle included measurements at 5 different SS $(0.07 \%, 0.10 \%$, $0.20 \%, 0.40 \%$ and $0.80 \%$ ) where 20 min for $0.07 \%$ and 10 min for each of the rest. Therefore, the $N_{\mathrm{CCN}}$ for five SS were available every hour. Here $10 \mathrm{~min}$ per SS can make sure at least twice replicates, as $\mathrm{CCN}$ temperature transients during SS changes may produce unreliable spectra if they occur during a voltage up-scan (Moore et al., 2010). Whenever the temperature gradient is changed, up to 2 minutes are required for the instrument profiles to stabilize.

The Dual CCN counter was calibrated regularly with size selected (by DMA) ammonium sulfate particles (Rose et al., 2008; Deng et al., 2011) before and after the campaign. The critical dry diameters $(50 \%$ of the particles activated) determined from the activation curves of ammonium sulfate under diffent tempetature gradients (TG), are converted to SS utilizing the Köhler equation where several Köhler theory parameter employed (Seinfeld and Pandis, 2006; Young and Warren, 1992; Low, 1969). TG and SS were linearly fitted. The SS of CCN is calculated from the TG-SS linearly fitted function.

The aerosol chemical composition of the non-refractory submicron particles is measured by an Aerodyne Compact Time-of-Flight Aerosol Mass Spectrometer (C-ToF-AMS). The details description of the C-ToF-AMS and its operation has been presented in many previous publications and reviewed by Drewnick et al. (2005). In short, ambient aerosol is focused through an aerodynamic lens assembly into a narrow particle beam for sizes between $50 \mathrm{~nm}$ and $600 \mathrm{~nm}$ efficiently (Zhang et al., 2002, 2004). Smaller and larger particles are also collected, but with lower efficiently. Particle size information is obtained by measuring particle velocity with a mechanical chopper wheel. The particles impact on an inverted conical tungsten vapour, where the nonrefractory components are flash vapour. Then the resulting gas is ionised by electron ionization at $70 \mathrm{eV}$. The ions are subsequently extracted orthogonally and sampled by the CToFMS (Tofwerk AG, Thun, Switzerland) for mass analysis. The instrument provides 2 min averaged quantitative mass loading information on non-refractory components using a well characterised series of calibrations and error estimations (Jimenez et al., 2003; Allan et al., 2003, 2004), as well as species resolved size distributions. The C-ToF-AMS calibration, e.g. inlet flow, ionization efficiency (IE) and particle sizing, was performed at the beginning, the middle and the end 
of the campaign as the standard protocols recommend (Jayne et al., 2000; Jimenez et al., 2003; Drewnick et al., 2005).

\subsection{Date processiong}

The $\mathrm{CN}$ and $\mathrm{CCN}$ time series distribution is obtained by using the TSI Aerosol Instrument Manager (AIM) software (Wang and Flagan, 1989) and CCN acquiring software respectively. AIM can provide the raw $\mathrm{CN}$ counts reported by the CPC every $0.1 \mathrm{~s}$ during each scan cycle and $\mathrm{CCN}$ acquiring software record data every second. Here data collected during the voltage upscan was employed to inversion. The detail description of the application of Scanning Mobility CCN Analysis (SMCA) and the CCN activation ratio calculation are introduced by Moore et al. (2010). Firstly, the time series distribution of $\mathrm{CN}$ and $\mathrm{CCN}$ is aligned by matching the minimum in counts that occurs during the transition between upscan and downscan. Then the $\mathrm{CN}$ and $\mathrm{CCN}$ time series is converted to size space using the size-scan time relationship provided by the AIM software, the inverted sizeresolved aerosol number distribution is obtained. Finally, a multiple charged correction is applied for the CCN activation ratio calculation due to the presence of multiply charged particles which will result higher measured activation ratio especially for these smaller particle sizes.

The C-ToF-AMS usually have two different operational mode: The MS (Mass Spectrum) mode which is used to collect averaged mass spectra of the non-refractory aerosol and can provide mass concentrations for several species such as sulfate, nitrate, ammonium, chloride and total nonrefractory organics, and the P-ToF (Particle Time-of-Flight) mode which is used to collect averaged size distribution data for all non-refractory aerosol and can calculate size distributions for each species independently. Therefore, the CToF-AMS can provide redundant as well as complementary information of chemistry and size distribution for the nonrefractory aerosol. Details of the inversions are presented by Drewnick et al. (2005) and DeCarlo et al. (2006).

\section{Results and discussion}

\subsection{Sampling data}

Figure 1 shows the sampling data at downtown Tianjin during 1-7 and 15-23 September 2010. The hourly-averaged mass concentration of aerosol particles observed by AMS range from 4 to $251 \mu \mathrm{g} \mathrm{cm}^{-3}$, with averaged mass concentration of $66 \pm 50 \mu \mathrm{g} \mathrm{cm}^{-3}$. Large variation of aerosol composition was observed during this experiment. Hourlyaveraged organics fraction range from $1.1 \%$ to $63.8 \%$, with $82 \%$ data ranges from $10-60 \%$. The averaged mass component of aerosols during the experiment are: organics, $23.8 \%$; sulfate $\left(\mathrm{SO}_{4}\right), 21.8 \%$; nitrite $\left(\mathrm{NO}_{3}\right), 24.6 \%$; ammonia (NH4), $20.6 \%$; chlorine $(\mathrm{Cl}), 9.2 \%$. The number concentration of aerosol particles with size of $14.1-736.5 \mathrm{~nm}$
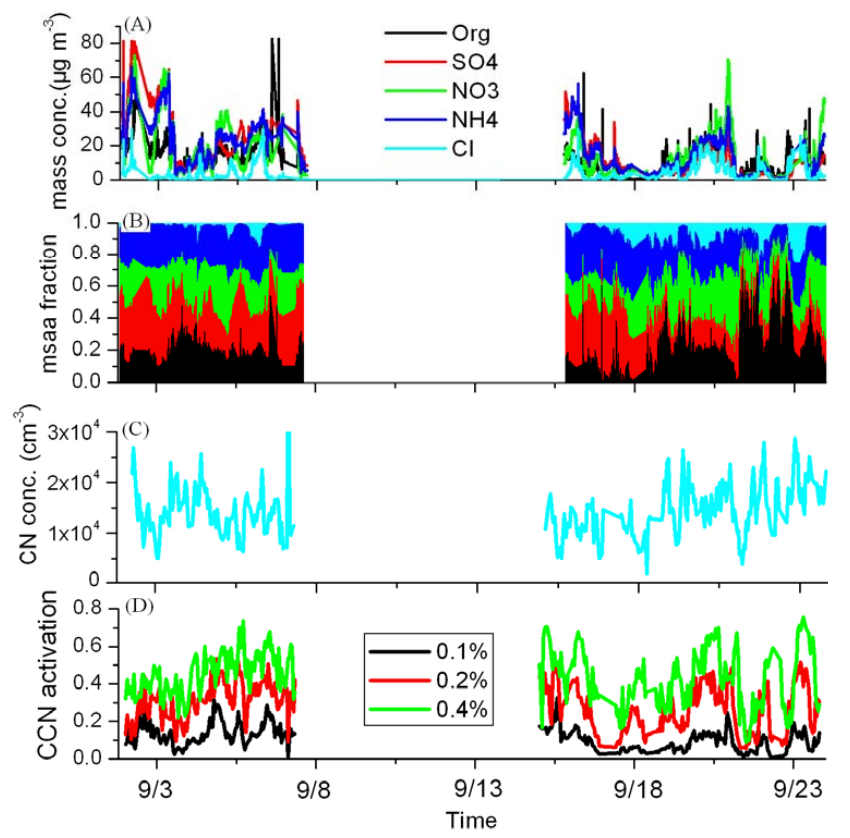

Fig. 1. The mass concentration (A), mass fraction (B) of aerosol particles observed by AMS, CN number concentration (C), and the $\mathrm{CCN}$ activation (CCN/CN) (D) of aerosols during the experiment.

observed by SMPS range from 2416 to $32396 \mathrm{~cm}^{-3}$ with averaged value of $13117 \pm 4797 \mathrm{~cm}^{-3}$. The averaged number concentrations of CCN under SS of $0.1 \%, 0.2 \%, 0.4 \%$ are $1489 \pm 982 \mathrm{~cm}^{-3}, 4121 \pm 2725 \mathrm{~cm}^{-3}, 6640 \pm 6791 \mathrm{~cm}^{-3}$ respectively. Large variation of $\mathrm{CCN} / \mathrm{CN}$ was also observed during this experiment. The $\mathrm{CCN} / \mathrm{CN}$ under SS of $0.1 \%, 0.2 \%, 0.4 \%$ range from $0.6 \%-32.6 \%, 5.2 \%-55.6 \%$, $8.8 \%-75.7 \%$ respectively.

\subsection{Effect of aerosol composition on $\mathrm{CCN}$ activity}

$\mathrm{CCN}$ is the aerosol particles that can grow into cloud droplets (activate) under atmospheric SS. The SS needed to activate the particles is called critical supersaturation $(\mathrm{Sc})$. Based on Köhler theory, for particles of constant size, the Sc depend on their solubility, which is a function of its composition (Dusek et al., 2006), including the number of potential solute molecules and their solubility. For example, the Sc needed to activate the particles of ammonium sulfate, adipic acid with size of $100 \mathrm{~nm}$ is $0.15 \%$ and $0.27 \%$ respectively (Hings et al., 2008). With the increasing of SS, the CCN/CN will increase correspondingly. Therefore, the SS should also be concerned in studying the $\mathrm{CCN}$ activation of environment aerosols. If the SS was set too high in the experiment, the properties of aerosol particles might be covered. In the atmosphere, aerosol particles are most likely to be mixtures of organic and inorganic components. Based on Köhler theory, the $\mathrm{Sc}$ needed for inorganic salts to activate to $\mathrm{CCN}$ is lower than organics for the same size of particles due to the high 

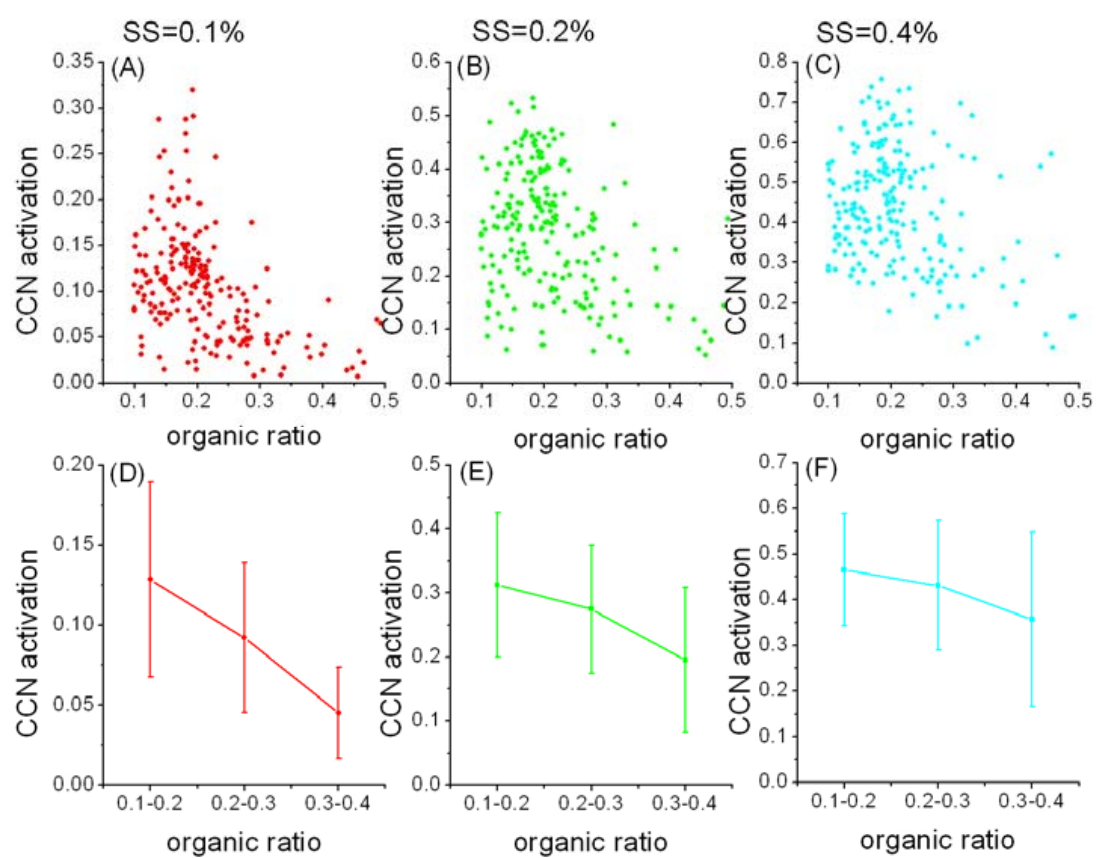

Fig. 2. The relation of $\mathrm{CCN} / \mathrm{CN}$ with organics fraction under $\mathrm{SS}$ of $0.1 \%, 0.2 \%$ and $0.4 \%$ respectively.
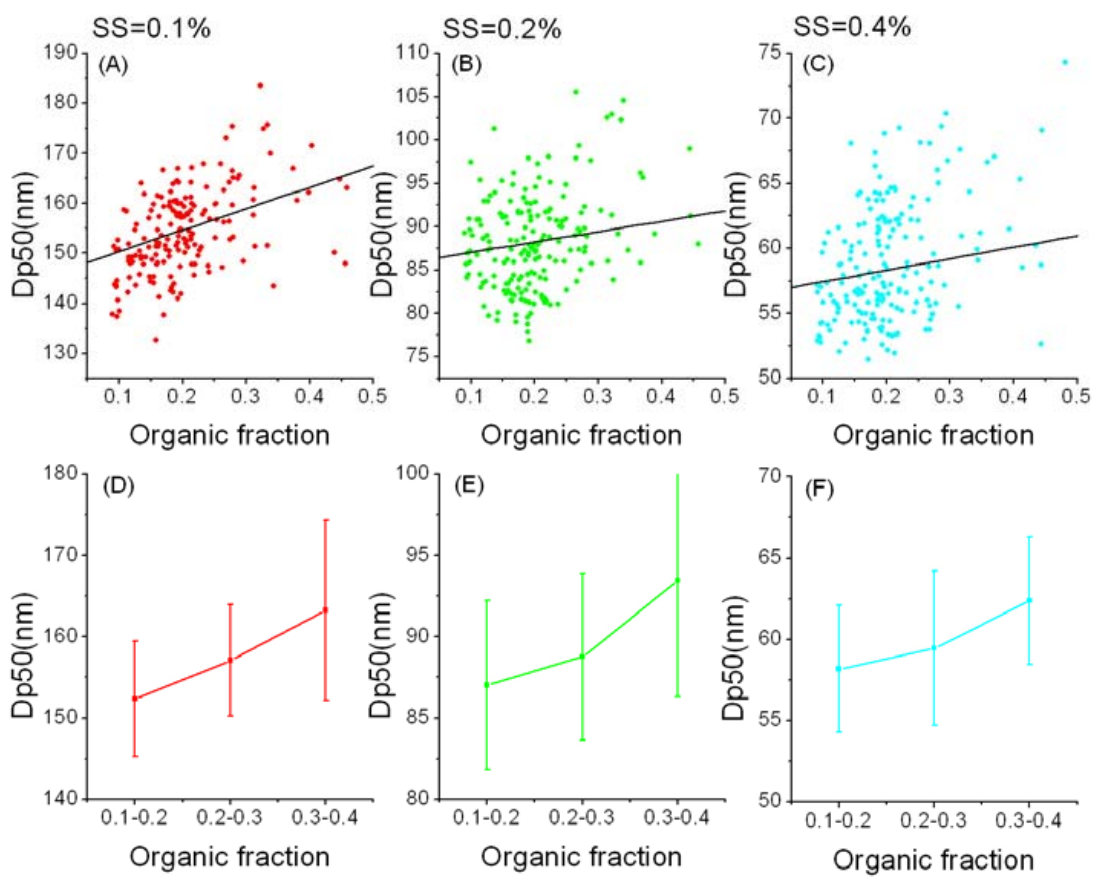

Fig. 3. The relation of $D_{p 50}$ with organics fraction under SS of $0.1 \%, 0.2 \%$ and $0.4 \%$ respectively.

solubility of inorganic salts, which make particles with more inorganic salts will be easier to be activated under the same condition. In this study, the organics fraction measured by AMS was used to analyze the effect of aerosol composition on CCN activity.

Figures 2 and 3 shows the relation of $\mathrm{CCN} / \mathrm{CN}$, and the diameter of particles at $\mathrm{CCN} / \mathrm{CN}=0.5\left(\mathrm{D}_{p 50}\right)$ with organ- ics fraction under the three SS respectively. Under a certain SS, the CCN/CN decreased with the raising of organics fraction. Moreover the decreasing trend is more effective under lower SS. For example, under SS of $0.1 \%$, the $\mathrm{CCN} / \mathrm{CN}$ increases from $4.5 \pm 2.6 \%$ to $12.8 \pm 6.1 \%$ when organics fraction decrease from $30-40 \%$ to $10-20 \%$. The rate of increase reached up to $184 \%$. While under SS of 


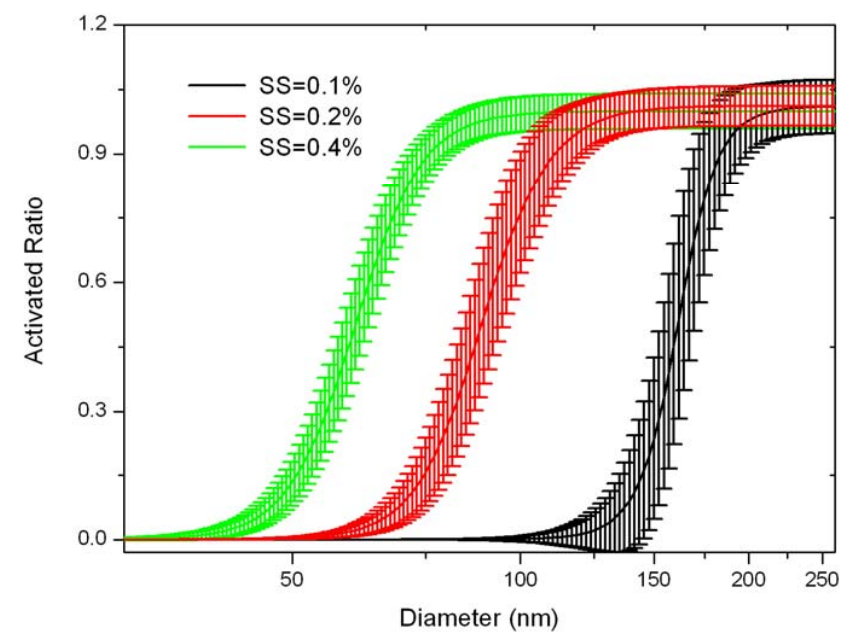

Fig. 4. The size-resolved CCN activation of aerosol particles under SS of $0.1 \%, 0.2 \%$ and $0.4 \%$ respectively.

$0.4 \%$, the CCN activity increases only from $35.7 \pm 19.0 \%$ to $46.5 \pm 12.3 \%$ correspondingly, and the rate of increase decreased to $30.1 \%$. In Fig. 2 the size of particles were not included. To analyze the influence of particles size on CCN activity under different aerosol composition, we compare the relation of $\mathrm{D}_{p 50}$ with organics fraction. The $\mathrm{D}_{p 50}$ increased correspondingly with the raising of organics fraction, indicating that less particle will be converted to $\mathrm{CCN}$. For example, under SS of $0.1 \%$, the $\mathrm{D}_{p 50}$ increase from $152.3 \pm 7.1 \mathrm{~nm}$ to $163.4 \pm 11.1 \mathrm{~nm}$ when organics fraction raised from $10-20 \%$ to $30-40 \%$. The extent of increase is $11.1 \mathrm{~nm}$. While under SS of $0.2 \%$, the extent of increase declines to $6.5 \mathrm{~nm}$, and further declines to $4.2 \mathrm{~nm}$ at SS of $0.4 \%$.

\subsection{Size-resolved activation ratio}

Based on the observation and method introduced in Sect. 2, we first calculated the CCN activity (Fig. 4) and their stand deviation (SD) (Fig. 5) under the three SS without consideration of aerosol composition. The stand deviation (SD) of the spectrum about CCN activity is defined as follow:

$\mathrm{SD}=\left(\sum(r-\bar{r})^{2} / N\right)^{1 / 2}$

Where $r$ is the ratio of $\mathrm{CCN}$ to $\mathrm{CN}, \bar{r}$ is averaged data, and $N$ is sample number.

Figure 4 shows that the $\mathrm{CCN}$ activity is sensitive highly to SS for particles with size of 50-200 nm, which is the dominated part of aerosol particles. For example, for particles with size of $100 \mathrm{~nm}$, the $\mathrm{CCN} / \mathrm{CN}$ is near to 0 at SS of $0.1 \%$, and increases to 0.75 at SS of $0.2 \%$, further increases to near 1.0 at SS of $0.4 \%$. The SD in our observation fluctuates with SS and particles size. It decreased with the increasing of particles size for a certain SS, while the SD decreases with the increasing of SS for all particles (Fig. 5). For example, under

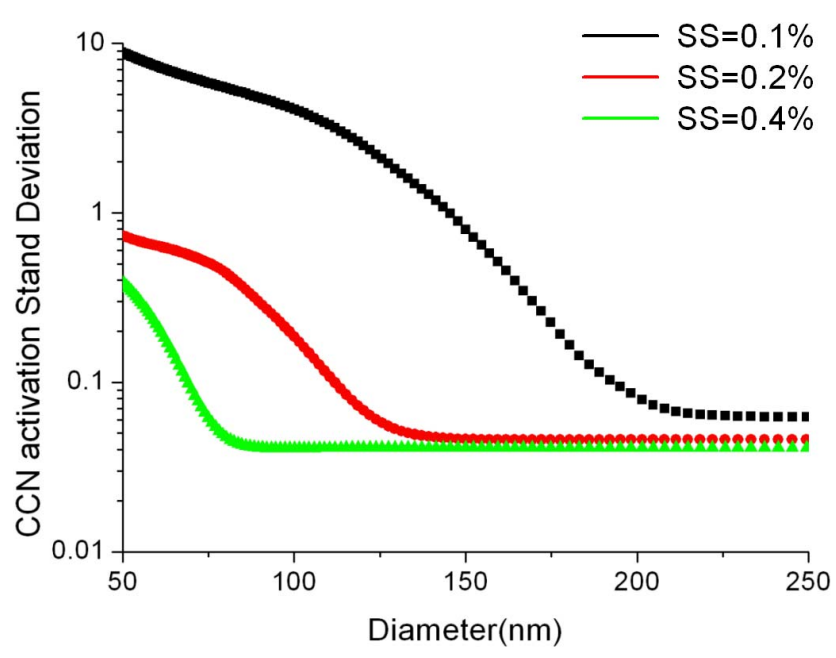

Fig. 5. The calculated stand deviation of size-resolved CCN activation under of $0.1 \%, 0.2 \%$ and $0.4 \%$ respectively

constant SS of $0.1 \%$, the SD is 4.2, 0.8, and 0.09 at size of $100 \mathrm{~nm}, 150 \mathrm{~nm}$ and $200 \mathrm{~nm}$. While for particles with size of $100 \mathrm{~nm}$, the SD is $0.04,0.2$, and 4.2 at SS of $0.4 \%, 0.2 \%$ and $0.1 \%$ respectively. The high SD for small particles $(50-$ $200 \mathrm{~nm})$ at low SS $(0.1 \%)$ might be caused by the variation of the aerosol composition since their effect on CCN activation is observed (Fig. 5), especially at low SS.

The $\mathrm{CCN}$ concentration $\left(N_{\mathrm{CCN}, \mathrm{Cal}}\right)$ can be calculated using the following equation,

$N_{\mathrm{CCN}, \mathrm{Cal}}=\int A\left(\log \mathrm{D}_{p}\right) n\left(\log \mathrm{D}_{p}\right) d \log \mathrm{D}_{p}$

Where $A\left(\log \mathrm{D}_{p}\right)$ is the size resolved activation ratio, and $n\left(\log \mathrm{D}_{p}\right)$ is the function of the aerosol number size distribution.

The calculated $N_{\mathrm{CCN}}$ based on Eq. (2), the size-resolved activation ratios (Fig. 4) and observed aerosol number size distribution is highly consistent with the measured $N_{\mathrm{CCN}}$ (Fig. 6) at high SS $\left(R^{2}=0.9925\right.$ at SS of $\left.0.4 \%\right)$ and the consistent decreased with decreasing of SS $\left(R^{2}=0.9480\right.$ at SS of $0.1 \%$ ). The linear fitted lines have slopes lower than 1 for each SS. The slopes are 0.708, 0.947, and 0.995 at SS of $0.1 \%, 0.2 \%$ and $0.4 \%$ respectively.

Above analysis indicated that the effect of aerosol composition on CCN can't be ignored in estimating the $\mathrm{CCN}$ concentration, especially at low SS which is present at natural environment. For example, the typical SS for stratiform clouds and fog are $0.05 \%$ and $0.1 \%$, respectively (Seinfeld and Pandis, 2006). To estimate quantitatively the contribution of aerosol composition on $\mathrm{CCN}$ calculated error, two cases of $\mathrm{CCN}$ closure study was analyzed with organics fraction of $24 \%$ and $55 \%$ at next part. 

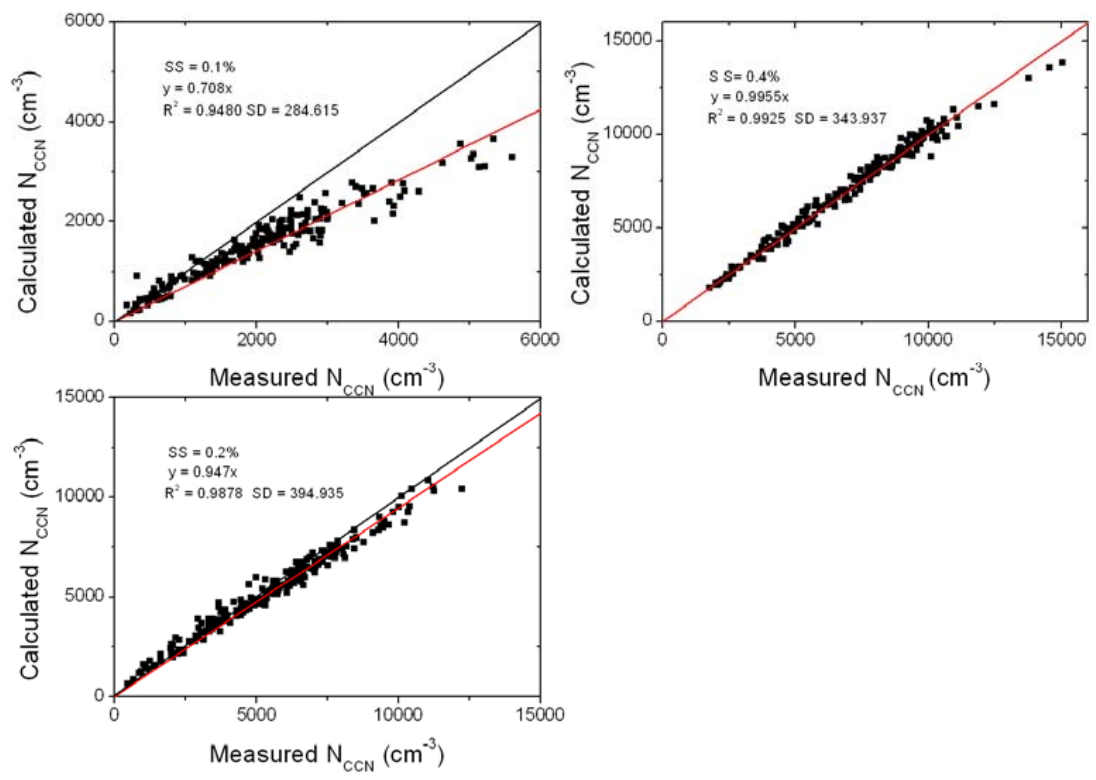

Fig. 6. Closure between measured $\mathrm{CCN}$ number concentration and the $\mathrm{CCN}$ Number concentration calculated from aerosol number size distribution and Size-resolved activation for the three SS.
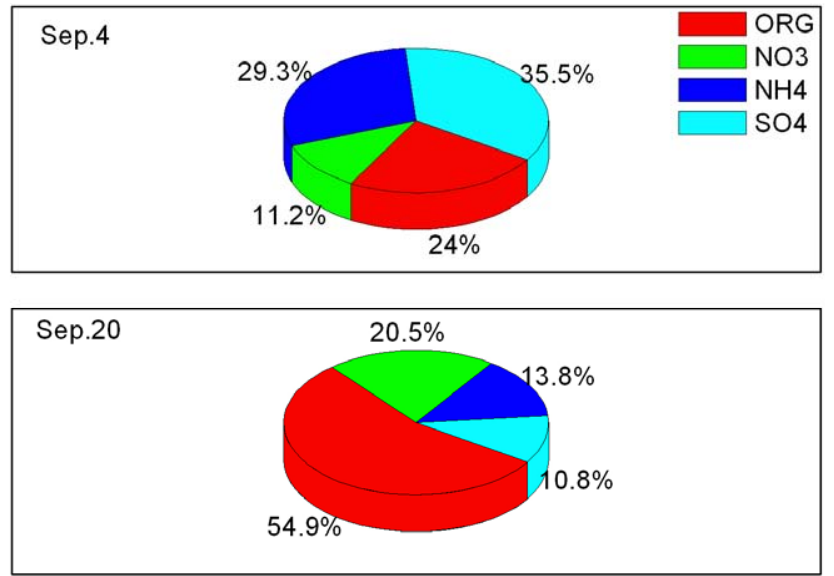

Fig. 7. The daily averaged composition of the two days with size ranging from 50 to $200 \mathrm{~nm}$ on 4 September and 20 September.

\subsection{Contribution of aerosol composition on $\mathrm{CCN}$ calculated error}

The selected two cases are 4 and 20 September Fig. 7 shows the daily averaged composition of the two days with size ranging from 50 to $200 \mathrm{~nm}$. On 4 September, inorganic is the dominated component, which takes up 60-80\% in mass concentration. While on 20 September, organic is the dominated component, which takes up $40-70 \%$ in mass concentration. The size-resolved CCN activation of aerosol particles under different SS calculation on methods introduced at Sect. 3.3 and observations of 4 and 20 September are shown in Fig. 8. There are significant difference of $\mathrm{CCN} / \mathrm{CN}$ for

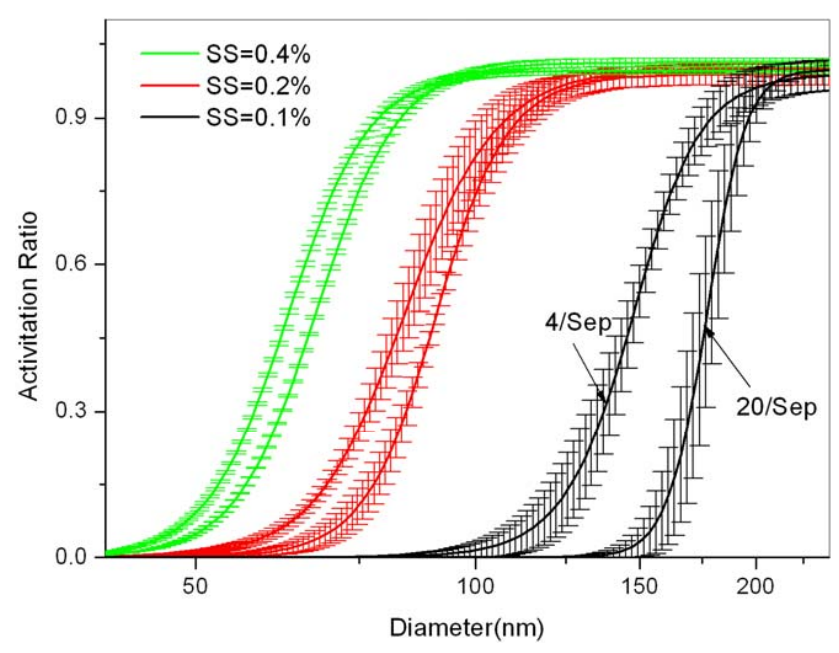

Fig. 8. The size-resolved CCN activation of aerosol particles under different SS for 4 September and 20 September.

particles size of $100-200 \mathrm{~nm}$ between the two cases under low SS $(0.1 \%)$. Moreover, the difference goes down with the increasing of SS. For example, for particles with size of $150 \mathrm{~nm}$, the CCN/CN is only 0.03 on 20 September, while it increase to 0.6 on 4 September. To estimate roughly the influence of aerosol composition on $\mathrm{CCN}$ activation, we calculate the $N_{\mathrm{CCN}}$ based on the $\mathrm{CCN}$ activation ratio get from the two cases at the same time and compare their difference. The calculated error is $31 \%$ at SS of $0.1 \%$, and decrease to $9 \%$ at SS of $0.2 \%$, and further decrease to $4 \%$ at SS of $0.4 \%$. Above results indicate that the influence of aerosol composition on $\mathrm{CCN}$ activation can't be neglected under low 
SS since their composition exist great regional and temporal difference (Zhang et al., 2009).

\section{Summaries}

A field experiment carried at downtown Tianjin during September 2010 to analyze the effect of aerosol composition on $\mathrm{CCN}$ activity. During this experiment $\mathrm{CCN}$ concentration under SS of $0.1 \%, 0.2 \%$ and $0.4 \%$, together with the aerosol size distribution and composition were simultaneously measured. Using the size and composition information, detailed CCN closure analyses under different SS were performed. The results are summarized as the follows:

1. The critical SS (Sc), which is the threshold SS for CCN activation, is affected by their composition. Only when environmental SS is higher than their Sc can the particles be activated. Based on Köhler theory, the Sc decreased with increasing particles solubility. Therefore, the effect of aerosol composition on CCN activity is significant at low SS, and this effect decreased with the raising of SS. If the SS was set too high, most particles can be activated. This point was verified in our experiment. In this study, the fraction of organic component was used to represent character of aerosol composition in analyzing their influence on CCN activity. The observations indicated that the $\mathrm{CCN}$ activity decreased, and the $\mathrm{D}_{p 50}$ increased with the raising of organic fraction. Moreover the decreasing trend is more effective under lower SS. For example, under SS of $0.1 \%$, the $\mathrm{CCN}$ activity increases from $4.5 \pm 2.6 \%$ to $12.8 \pm 6.1 \%$ when organics fraction decrease from $30-40 \%$ to $10-20 \%$. The rate of increase reached up to $184 \%$. While under SS of $0.4 \%$, the CCN activity increases only from $35.7 \pm 19.0 \%$ to $46.5 \pm 12.3 \%$ correspondingly.

2. Regardless of aerosol composition, the calculated $N_{\mathrm{CCN}}$ based on the aerosol number size distribution and the size-resolved activation ratios is consistent with observed $N_{\mathrm{CCN}}$ at high SS $(0.4 \%)$, but this consistence decreased with the falling of SS. Moreover, the stand deviation (SD) of calculated $N_{\mathrm{CCN}}$ increased with the decreasing of SS. The slopes of linear fitted lines between calculated $N_{\mathrm{CCN}}$ and observed $N_{\mathrm{CCN}}$ are 0.708 , 0.947 , and 0.995 at SS of $0.1 \%, 0.2 \%$ and $0.4 \%$ respectively.

3. The contribution of aerosol composition on CCN activity was estimated quantitatively based on $\mathrm{CCN}$ closure study of two cases with organic fraction of $24 \%$ and $55 \%$. The calculated error is estimated on the difference of the calculated $N_{\mathrm{CCN}}$ based on size-resolved activation ratios got from the two cases. The result indicated that the calculated error of $N_{\mathrm{CCN}}$ could reach up to $34 \%$ at SS of $0.1 \%$ and calculated error decreased with the raising of SS. It is decreased to $9 \%$ at SS of $0.2 \%$, and further decreased to $4 \%$ at SS of $0.4 \%$.

Acknowledgements. This research is partially supported by National Natural Science Foundation of China (NSFC) under Grant No. 40905060 and No. 41175007; The National Basic Research Program of China (2011CB403401); The project of scientific and technological new star of Beijing under Grant No. 2010B029; China Meteorological Administration (CMA) under Grant No. GYHY200806001-4.

Edited by: X. Tie

\section{References}

Allan, J. D., Jimenez, J. L., Coe, H., Bower, K. N., Williams, P. I., and Worsnop, D. R.: Quantitative sampling using an aerodyne aerosol mass spectrometer. Part 1: Techniques of data interpretation and error analysis, J. Geophys. Res. Atmos., 108, 4090, doi:10.1029/2002JD002358, 2003.

Allan, J. D., Coe, H., Bower, K. N., Alfarra, M. R., Delia, A. E., Jimenez, J. L., Middlebrook, A. M., Drewnick, F., Onasch, T. B., Canagaratna, M. R., Jayne, J. T., and Worsnop, D. R.: Technical note: extraction of chemically resolved mass spectra from aerodyne aerosol mass spectrometer data, J. Aerosol Sci., 35, 909922, 2004.

Andreae, M. O., Rosenfeld, D., Artaxo, P., Costa, A. A., Frank, G. P., Longo, K. M., and Silva-Dias, M. A. F.: Smoking rain clouds over the Amazon, Science, 303, 1337-1342, 2004.

Broekhuizen, K., Kumar, P. P., and Abbatt, J. P. D.: Partially soluble organics as cloud condensation nuclei: Role of trace soluble and surface active species, Geophys. Res. Lett., 31, L01107, doi:10.1029/2003GL018203, 2004.

Brooks, S. D., Garland, R. M., Wise, M. E., Prenni, A. J., Cushing, M., Hewitt, E., and Tolbert, M. A.: Phase changes in internally mixed maleic acid/ammonium sulfate aerosols, J. Geophys. Res., 108, 4487, doi:10.1029/2002JD003204, 2003.

Cruz, C. N. and Pandis, S. N.: The effect of organic coatings on the cloud condensation nuclei activation of inorganic atmospheric aerosol, J. Geophys. Res., 103, 13111-13123, 1998.

DeCarlo, P. F., Kimmel, J. R., Trimborn, A., Northway, M. J., Jayne, J. T., Aiken, A. C., Gonin, M., Fuhrer, K., Horvath, T., Docherty, K. S., Worsnop, D. R., and Jimenez, J. L.: Field-deployable, high-resolution, time-of-flight aerosol mass spectrometer, Anal. Chem., 78, 8281-8289, 2006.

Deng, Z. Z., Zhao, C. S., Ma, N., Liu, P. F., Ran, L., Xu, W. Y., Chen, J., Liang, Z., Liang, S., Huang, M. Y., Ma, X. C., Zhang, Q., Quan, J. N., Yan, P., Henning, S., Mildenberger, K., Sommerhage, E., Schäfer, M., Stratmann, F., and Wiedensohler, A.: Size-resolved and bulk activation properties of aerosols in the North China Plain, Atmos. Chem. Phys., 11, 3835-3846, doi:10.5194/acp-11-3835-2011, 2011.

Drewnick, F., Hings, S. S., DeCarlo, P., Jayne, J. T., Gonin, M., Fuhrer, K., Weimer, S., Jimenez, J. L., Demerjian, K. L., Borrmann, S., Worsnop, D. R.: A new Time-of-Flight Aerosol Mass Spectrometer (TOF-AMS)-instrument description and first field deployment, Aerosol Sci. Technol., 39, 637-658, 2005.

Dusek, U., Frank, G. P., Hildebrandt, L., Curtius, J., Schneider, J., Walter, S., Chand, D., Drewnick, F., Hings, S., Jung, D., Bor- 
rmann, S., and Andreae, M. O.: Size matters more than chemistry for cloud nucleating ability of aerosol particles, Science, 312, 1375-1378, 2006.

Hegg, D. A., Gao, S., Hoppel, W., Frick, G., Caffrey, P., Leaitch, W. R., Shantz, N., Ambrusko, J., and Albrechcinski, T.: Laboratory studies of the efficiency of selected organic aerosols as $\mathrm{CCN}$, Atmos. Res., 58, 155-166, 2001.

Henning, S., Rosenørn, T., D’Anna, B., Gola, A. A., Svenningsson, B., and Bilde, M.: Cloud droplet activation and surface tension of mixtures of slightly soluble organics and inorganic salt, Atmos. Chem. Phys., 5, 575-582, doi:10.5194/acp-5-575-2005, 2005.

Hings, S. S., Wrobel, W. C., Cross, E. S., Worsnop, D. R., Davidovits, P., and Onasch, T. B.: CCN activation experiments with adipic acid: effect of particle phase and adipic acid coatings on soluble and insoluble particles, Atmos. Chem. Phys., 8, 37353748, doi:10.5194/acp-8-3735-2008, 2008.

IPCC: Climate Change 2007: The Physical Science Basis, Cambridge University Press, Cambridge, United Kingdom and New York, NY, USA, 996 pp., 2007.

Jayne, J. T., Leard, D. C., Zhang, X., Davidovits, P., Smith, K. A.,Kolb, C. E., and Worsnop, D. R.: Development of an Aerosol Mass Spectrometer for Size and Composition, Analysis of Submicron Particles, Aerosol Sci. Technol., 33, 49-70, 2000.

Jin, M. and Shepherd, J. M.: Aerosol relationships to warm season clouds and rainfall at monthly scales over east China: Urban land versus ocean, J. Geophys. Res., 113, D24S90, doi:10.1029/2008JD010276, 2008.

Jimenez, J. L., Jayne, J. T., Shi, Q., Kolb, C. E., Worsnop, D. R., Yourshaw, I., Seinfeld, J. H., Flagan, R. C., Zhang, X., Smith, K. A., Morris, J. W., and Davidovits, P.: Ambient aerosol sampling using the Aerodyne aerosol mass spectrometer, J. Geophys. Res., 108, 8425, doi:10.1029/2001JD001213, 2003.

Kulmala, M., Laaksonen, A., Charlson, R. J., and Korhonen, P.: Clouds without supersaturation, Nature, 388, 336-337, 1997.

Kumar, P. P., Broekhuizen, K., and Abbatt, J. P. D.: Organic acids as cloud condensation nuclei: Laboratory studies of highly soluble and insoluble species, Atmos. Chem. Phys., 3, 509-520, doi:10.5194/acp-3-509-2003, 2003.

Lance, S., Medina, J., Smith, J. N., and Nenes, A.: Mapping the operation of the dmt continuous flow CCN counter, Aerosol Sci. Tech., 40, 242-254, 2006.

Low, R. D. H.: A generalized equation for the solution effect in droplet 1 growth, J. Atmos. Sci., 26, 608-611, 1969.

Marcolli, C., Luo, B. P., and Peter, T.: Mixing of the organic aerosol fractions: Liquids as the thermodynamically stable phases, J. Phys. Chem., 108, 2216-2224, 2004.

Moore, R. H., Nenes, A., and Medina, J.: Scanning mobility CCN analysis - a method for fast measurements of size-resolved CCN distributions and activation kinetics, Aerosol Sci. Tech., 44, 861$871,2010$.

Prenni, A. J., DeMott, P. J., Kreidenweis, S. M., Sherman, D. E., Russell, L. M., and Ming, Y.: The effects of low molecular weight dicarboxylic acids on cloud formation, J. Phys. Chem., 105, 11240-11248, 2001.
Ramanathan, V., Crutzen, P. J., Lelieveld, J., Mitra, A. P., Althausen, D., Anderson, J., Andreae, M. O., Cantrell, W., Cass, G. R., Chung, C. E., Clarke, A. D., Coakley, J. A., Collins, W. D., Conant, W. C., Dulac, F., Heintzenberg, J., Heymsfield, A. J., Holben, B., Howell, S., Hudson, J., Jayaraman, A., Kiehl, J. T., Krishnamurti, T. N., Lubin, D., McFarquhar, G., Novakov, T., Ogren, J. A., Podgorny, I. A., Prather, K., Priestley, K., Prospero, J. M., Quinn, P. K., Rajeev, K., Rasch, P., Rupert, S., Sadourny, R., Satheesh, S. K., Shaw, G. E., Sheridan P., and Valero F. P. J.: Indian Ocean Experiment: An integrated analysis of the climate forcing and effects of the great Indo-Asian haze, J. Geophys. Res., 106, 28371-28399, 2001.

Raymond, T. M. and Pandis, S. N.: Formation of cloud droplets by multicomponent organic particles, J. Geophys. Res., 108, 4469, doi:10.1029/2003JD003503, 2003.

Roberts, G. C. and Nenes, A.: A continuous-flow streamwise thermal-gradient $\mathrm{CCN}$ chamber for atmospheric measurements, Aerosol Sci. Tech., 39, 206-221, 2005.

Rose, D., Gunthe, S. S., Mikhailov, E., Frank, G. P., Dusek, U., Andreae, M. O., and Pöschl, U.: Calibration and measurement uncertainties of a continuous-flow cloud condensation nuclei counter (DMT-CCNC): CCN activation of ammonium sulfate and sodium chloride aerosol particles in theory and experiment, Atmos. Chem. Phys., 8, 1153-1179, doi:10.5194/acp-8-11532008, 2008.

Rosenfeld, D., Lohmann, U., Raga, G. B., O’Dowd, C. D., Kulmala, M., Fuzzi, S., Reissell, A., and Andreae, M. O.: Flood or Drought: How Do Aerosols Affect Precipitation?, Science, 321, 1309-1313, 2008.

Seinfeld, J. H. and Pandis, S. N.: Atmospheric chemistry and physics: From air pollution to climate change, 2 ed., John Wiley \& Sons, Inc., 1225 pp., 2006.

Wang, S. and Flagan, R.: Scanning electrical mobility spectrometer, J. Aerosol Sci., 20, 1485-1488, 1989.

Young, K. C. and Warren, A. J.: A reexamination of the derivation of the equilibrium supersaturation curve for soluble particles, J. Atmos. Sci., 49, 1138-1143, 1992.

Zhang, Q., Ma, X., Tie, X., Huang, M., and Zhao, C.: Vertical Distributions of Aerosols under Different Weather Conditions: Analysis of In-situ Aircraft Measurements in Beijing, China, Atmos. Environ., 43, 5526-5535, 2009.

Zhang, Q., Quan, J., Tie, X., Huang, M., and Ma, X.: Impact Aerosol Particles on Cloud Formation: Aircraft Measurements in Beijing, China, Atmos. Environ., 45, 665-672, 2011.

Zhang, X., Smith, K. A., Worsnop, D. R., Jimenez, J. L., Jayne, J. T., and Kolb, C. E.: A numerical characterization of particle beam collimation by an aerodynamic lens-nozzle system. Part I: An individual lens or nozzle, Aerosol Sci. Technol., 36, 617-631, 2002.

Zhang, X., Smith, K. A., Worsnop, D. R., Jimenez, J. L., Jayne, J. T., Kolb, C. E., Morris, J., and Davidovits, P.: Numerical characterization of particle beam collimation: Part II: Integrated aerodynamic lens-nozzle system, Aerosol Sci. Technol., 38, 619638, 2004. 